\title{
Effect of Mo on Dynamic Recrystallization Behavior of Nb-Mo Microalloyed Steels
}

\author{
B. PEREDA, ${ }^{1)}$ A. I. FERNÁNDEZ, ${ }^{2)}$ B. LÓPEZ1) and J. M. RODRIGUEZ-IBABE ${ }^{1)}$ \\ 1) CEIT and Tecnun (Univ. of Navarra), $P^{\circ}$ M. Lardizabal 15, E-20018 San Sebastián, Basque Country, Spain. \\ E-mail: jmribabe@ceit.es $\quad$ 2) Formerly CEIT and Tecnun (Univ. of Navarra). Now at Azterlan, Aliendalde 6, 48200 \\ Durango, Basque Country, Spain.
}

(Received on January 10, 2007; accepted on March 16, 2007)

\begin{abstract}
The influence of the Mo addition on the dynamic recrystallization behavior of $\mathrm{Nb}$ microalloyed steels was studied. The initial austenite grain size, the amount of microalloying elements in solid solution and the deformation conditions (temperature and strain rate) affect dynamic recrystallization kinetics of both $\mathrm{Nb}$ and $\mathrm{Nb}-\mathrm{Mo}$ steels. Continuous torsion tests were carried out to characterize the dynamic recrystallization behavior of the microalloyed austenite, after reheating the specimens at different temperatures between 1100 and $1460^{\circ} \mathrm{C}$, this brought a wide range of initial grain sizes, from 22 to $805 \mu \mathrm{m}$. It was observed that decreasing the values of the Zener-Hollomon parameter and of the initial grain size promotes dynamic recrystallization. Mo in solid solution produces a large retardation effect in the dynamic recrystallization and brings higher values in the characteristic critical, $\varepsilon_{\mathrm{c}^{\prime}}$ and peak, $\varepsilon_{\mathrm{p}}$, strains, being this effect independent of the Mo content. A corrective factor has been applied to quantify the retardation produced by Mo in solid solution. This means that it was possible to propose a unique relationship to predict the peak strain for $\mathrm{Nb}$, $\mathrm{Nb}-\mathrm{Ti}$ and $\mathrm{Nb}-\mathrm{Mo}$ steels.
\end{abstract}

KEY WORDS: dynamic recrystallization; hot direct rolling; Nb and Nb-Mo microalloyed steels.

\section{Introduction}

Mo is generally added to microalloyed steels containing $\mathrm{Nb}$ and/or $\mathrm{V}$ to attain higher levels of strength after hot rolling. ${ }^{1,2)}$ Hot rolled HSLA steels containing both $\mathrm{Nb}$ and Mo are generally used in special applications, pipelines and fire-resistant building frames. ${ }^{2)}$ Previous studies have shown that adding Mo to microalloyed steels can cause significant changes in the kinetics of the processes during hot working, for example austenite recrystallization and straininduced carbonitride precipitation. ${ }^{1-4)}$ It has been reported that Mo could decrease diffusivity of the carbide forming species (i.e. $\mathrm{Nb}, \mathrm{C}$ ), and thus delay the precipitation of $\mathrm{MC}$ carbides. $^{2,3)}$

This study concentrated on the influence of different Mo levels on the dynamic recrystallization kinetics of $\mathrm{Nb}$ microalloyed steels processed using thin slab casting technologies. It is well known that these processes bring economic advantages but there are significant differences compared to conventional rolling operations. ${ }^{5-10)}$ First, the metallurgical differences must be mentioned, above all the coarse grain size and the high supersaturation level of microalloying elements in the as-cast austenite..$^{5-7,11)}$ Then there are differences in the processing parameters, for example, a small number of passes are applied, but the strains in the initial stands are higher. ${ }^{7)}$ A consequence of these peculiarities is that under certain circumstances the conditions for the onset of dynamic recrystallization may be achieved. In fact, dynamic recrystallization has been proposed as one of the procedures that can be used to refine the as-cast microstructure during thin slab hot direct working. ${ }^{7-12)}$

The dynamic recrystallization (DRX) kinetics in C-Mn and microalloyed steels have been studied many times. ${ }^{13-18)}$ The onset of DRX during hot deformation occurs when a critical strain $\varepsilon_{\mathrm{c}}$ is reached. This critical strain is related to the peak strain $\varepsilon_{\mathrm{p}}$, i.e. the strain corresponding to the maximum stress in the flow curve, $\sigma_{\mathrm{p}}$, following a relationship of the type: $\varepsilon_{\mathrm{p}}=a \varepsilon_{\mathrm{c}}$. These characteristic strains depend on prior austenite grain size $\left(D_{\mathrm{o}}\right)$, strain rate $(\dot{\varepsilon})$, and temperature $(T)$, the latter two variables usually combined in the Zener-Hollomon parameter.

In a previous work the DRX kinetics of $\mathrm{Nb}$ and $\mathrm{Nb}-\mathrm{Ti}$ steels covering a wide austenite grain size range were studied. ${ }^{18)}$ Taking into account the effect of $\mathrm{Nb}$ and $\mathrm{Ti}$ in solution, the deformation parameters and the initial austenite grain size, Eq. (1) was deduced. ${ }^{18)}$

$$
\varepsilon_{\mathrm{p}}=3.7 \times 10^{-3} \frac{\{1+20([\mathrm{Nb}]+0.02[\mathrm{Ti}])\}}{1.78} D_{\mathrm{o}}^{0.147} Z^{0.155}
$$

where $[\mathrm{Nb}]$ and [Ti] are the respective niobium and titanium concentrations in solution (in mass \%) for each austenite state studied, $D_{\mathrm{o}}$ being the initial grain size and $Z$, the Zener-Hollomon parameter, calculated as $Z=$ $\left.\dot{\varepsilon} \exp \left(Q_{\text {def }} / R T\right), Q_{\text {def }}=325 \mathrm{~kJ} / \mathrm{mol}^{18}\right)$ With respect to the possible effect of Mo, there are some references pointing to the fact that Mo addition to microalloyed steels has a strong 
Table 1. Chemical compositions of the steels investigated (mass $\%$ ).

\begin{tabular}{lllllllllll}
\hline Steel & $\mathrm{C}$ & $\mathrm{Mn}$ & $\mathrm{Si}$ & $\mathrm{Nb}$ & $\mathrm{Mo}$ & $\mathrm{N}$ & $\mathrm{S}$ & $\mathrm{P}$ & $\mathrm{Al}$ & $\mathrm{Ti}$ \\
\hline $\mathbf{N b}$ & 0.1 & 1.42 & 0.31 & 0.035 & - & 0.0053 & 0.008 & 0.018 & 0.039 & $<0.005$ \\
\hline $\mathbf{N b}-M 015$ & 0.11 & 1.43 & 0.33 & 0.033 & 0.15 & 0.0054 & 0.013 & 0.018 & 0.023 & 0.007 \\
\hline Nb-Mo16 & 0.05 & 1.58 & 0.04 & 0.030 & 0.16 & 0.0048 & 0.002 & 0.011 & 0.027 & 0.001 \\
\hline Nb-Mo31a & 0.12 & 1.46 & 0.31 & 0.034 & 0.31 & 0.0058 & 0.012 & 0.019 & 0.025 & 0.004 \\
\hline Nb-Mo31b & 0.05 & 1.57 & 0.05 & 0.028 & 0.31 & 0.0055 & 0.002 & 0.010 & 0.028 & 0.002 \\
\hline
\end{tabular}

solute effect on the dynamic recrystallization kinetics leading to a significant retardation in the process. ${ }^{1-4)}$ However, this effect has not been yet quantified. This is an important issue, taking into account that any retardation of dynamic recrystallization could affect the design of the appropriate thin slab rolling sequences, above all for the initial stands, so that a correct refinement of the as-cast austenite can be achieved before niobium precipitation occurs. ${ }^{19)}$

This paper studied the DRX events for those steels containing $\mathrm{Nb}$ and $\mathrm{Mo}$ at the same time. A study was carried out to determine the effect of the initial austenite grain size, within a wide range of grain sizes, and the deformation conditions on DRX kinetics.

\section{Material and Experimental Procedure}

Four Nb-Mo microalloyed steels were studied and the results compared to a $\mathrm{Nb}$ microalloyed steel. A $0.035 \% \mathrm{Nb}$ microalloyed base steel and two levels of Mo, 0.15 and 0.31 , were considered. All the $\mathrm{Nb}-\mathrm{Mo}$ steels were experimental casts. The chemical compositions of the steels studied are listed in Table 1. The results obtained with the $\mathrm{Nb}$ steel were described in detail in a previous work ${ }^{18)}$ but they will be used here for assessing the individual and combined effects. Isothermal torsion tests were performed after soaking the specimen at different temperatures in the range of $1100-1460^{\circ} \mathrm{C}$ for $15 \mathrm{~min}$ in an argon atmosphere to analyze the DRX behavior. Torsion samples were machined from $40 \mathrm{~mm}$ thickness plates in the case of $\mathrm{Nb}, \mathrm{Nb}-\mathrm{Mo} 31 \mathrm{~b}$ and $\mathrm{Nb}-\mathrm{Mo} 16$ steels and from $40 \mathrm{~mm}$ diameter bars in the case of $\mathrm{Nb}-\mathrm{Mo} 31 \mathrm{a}$ and $\mathrm{Nb}-\mathrm{Mo} 15$ steels, respectively. Coarse austenite microstructures $(\approx 600-800 \mu \mathrm{m})$ were produced by reheating at high temperatures, in the range from 1400 to $1460^{\circ} \mathrm{C}$. After reheating, the specimens were cooled at $1^{\circ} \mathrm{C} / \mathrm{s}$ to different deformation temperatures: 1000,1100 and $1200^{\circ} \mathrm{C}$, held for $5 \mathrm{~min}$ at this temperature for stabilization, and then deformed at a strain rate in the range of 0.1 to $5 \mathrm{~s}^{-1}$. After deformation the specimens were water quenched for microstructural analysis. The microstructure evolution during deformation was also analyzed in steel $\mathrm{Nb}-\mathrm{Mo} 31 \mathrm{a}$ at two deformation conditions. For this purpose the tests were interrupted and the specimens water quenched after several specific deformations. The initial austenite grain size was determined from samples quenched after the soaking treatment. Metallographic measurements of quenched samples were carried out on a section corresponding to 0.9 of the outer radius of the torsion specimen, R, also known as the sub-surface section. ${ }^{20)}$

From the flow curves the characteristic parameters related to DRX were obtained: $\varepsilon_{\mathrm{p}}, \sigma_{\mathrm{p}}, \varepsilon_{\mathrm{ss}}$ and $\sigma_{\mathrm{ss}}$, the latter representing the strain at the onset of the steady state and

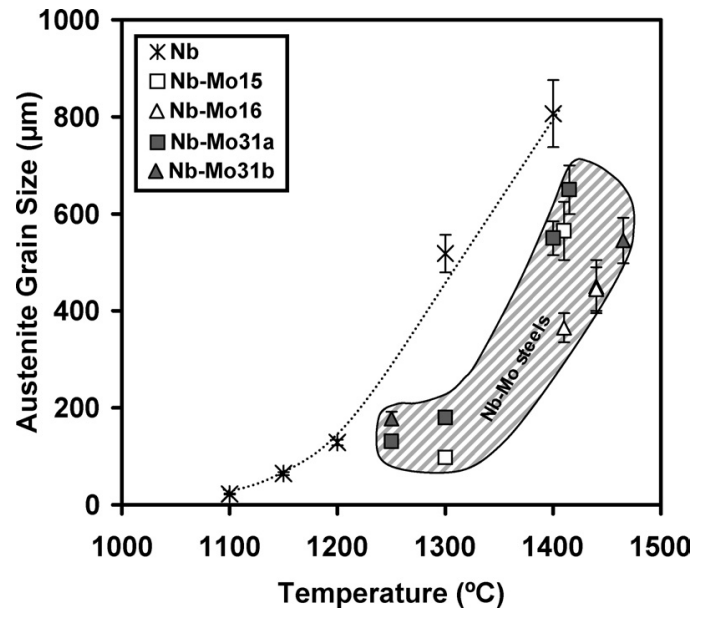

Fig. 1. Austenite grain growth as a function of the reheating temperature for $\mathrm{Nb}$ and $\mathrm{Nb}-\mathrm{Mo}$ steels.

the stress achieved in this region, respectively. The critical strain $\varepsilon_{\mathrm{c}}$ for DRX was calculated from the downward inflection point ${ }^{21)}$ in the $\theta(d \sigma / d \varepsilon)-\sigma$ experimental curve.

\section{Results}

Figure 1 shows the evolution of the austenite grain size with the reheating temperature for all the $\mathrm{Nb}-\mathrm{Mo}$ steels analyzed in the present work, together with previous data corresponding to the $\mathrm{Nb}$ base steel. ${ }^{18)}$ It can be observed that grain coarsening occurs at significantly higher temperatures for the $\mathrm{Nb}-\mathrm{Mo}$ steels. No differences have been observed in relation to the Mo content, with all the $\mathrm{Nb}-\mathrm{Mo}$ steels enclosed in the same region with respect to its grain coarsening behavior.

Figure 2 shows the flow curves obtained for the $\mathrm{Nb}-\mathrm{Mo} 31 \mathrm{la}$ steel deformed at $1100^{\circ} \mathrm{C}$ and $1200^{\circ} \mathrm{C}$ and a strain rate of $1 \mathrm{~s}^{-1}$ after reheating at different temperatures, leading to initial austenite grain sizes varying from 130 to $650 \mu \mathrm{m}$. In the figure the dynamically recrystallized fractions measured in samples quenched at different strains are also indicated. As the reheating temperature increases so do the initial austenite grain size and the amount of microalloying elements in solid solution, the curves show an increase in the $\varepsilon_{\mathrm{p}}$ peak strain. This is accompanied by a less pronounced fall in the stress after the peak resulting in larger strains for the onset of the steady state, $\varepsilon_{\mathrm{ss}}$, and the curves show a flatter shape. However $\sigma_{\mathrm{p}}$ and $\sigma_{\mathrm{ss}}$, the peak and steady-state stresses respectively, are very similar under the same deformation conditions for all the initial microstructures studied.

Figure 3 shows the effect of deformation temperature $\left(1000-1100^{\circ} \mathrm{C}\right)$ and strain rate $\left(0.1-1 \mathrm{~s}^{-1}\right)$ on the stress- 


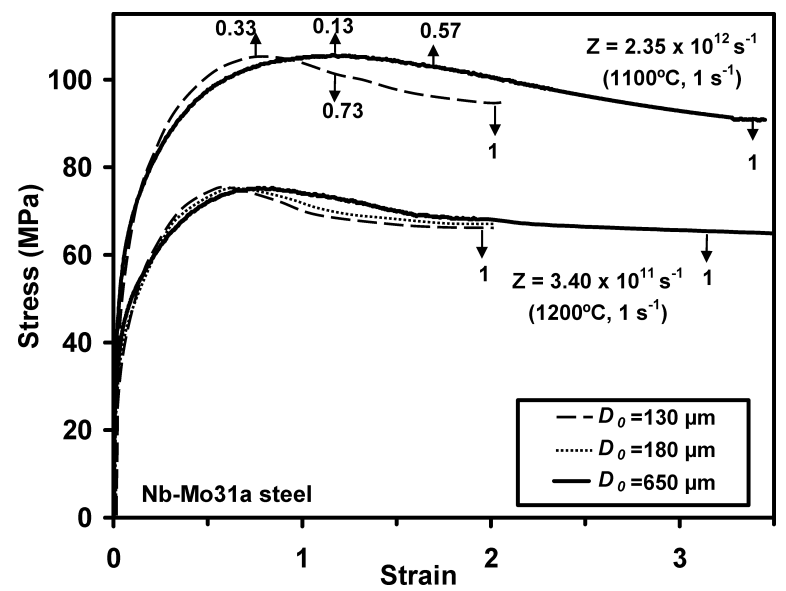

Fig. 2. Stress-strain curves Nb-Mo3la steel tested at different initial austenite grain sizes at two deformation conditions. The dynamically recrystallized fraction measured in samples quenched after different deformations is indicated.

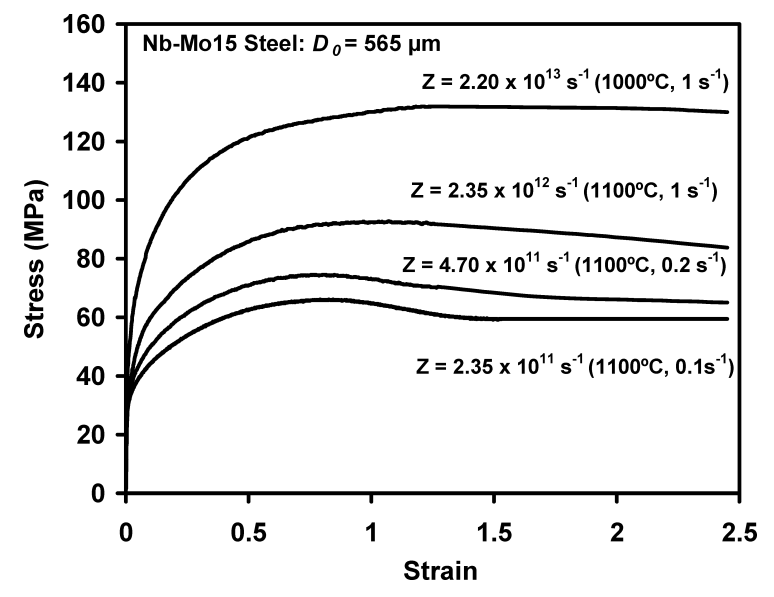

Fig. 3. Effect of deformation temperature and strain rate on the flow curves for $\mathrm{Nb}-\mathrm{Mo} 15$ steel reheated at $1410^{\circ} \mathrm{C}$ $\left(D_{\mathrm{o}}=565 \mu \mathrm{m}\right)$.

strain curves for the $\mathrm{Nb}-\mathrm{Mo} 15$ steel reheated at $1410^{\circ} \mathrm{C}$ $\left(D_{\mathrm{o}}=565 \mu \mathrm{m}\right)$. For the higher deformation temperature $\left(1100^{\circ} \mathrm{C}\right)$ and all the strain rates used, the curves exhibit the classical shape, with a well defined peak flow stress followed by a work-softening and a steady-state region, denoting that DRX is taking place. However, at the lowest temperature of $1000^{\circ} \mathrm{C}$, although dynamic recrystallization also took place the peak occurrence is difficult to observe due to the flattened shape of the curve. As strain rate increases, or as deformation temperature decreases, the curves move to higher stress values and both the peak and the steady state occur at higher strains, the strain difference $\varepsilon_{\mathrm{ss}}-\varepsilon_{\mathrm{p}}$ increasing as well.

The influence of the addition of Mo to the $\mathrm{Nb}$ base steel on the stress-strain curves for three different deformation conditions is illustrated in Fig. 4. In the three cases the initial austenite grain size is similar for $\mathrm{Nb}$ and $\mathrm{Nb}-\mathrm{Mo}$ steels. It can be seen that when Mo is added to the $\mathrm{Nb}$ steels although the peak stresses remain similar, there is an increase in the $\varepsilon_{\mathrm{p}}$ peak strain. This is accompanied by a less pronounced fall in the stress after the peak, leading to larger $\varepsilon_{\mathrm{ss}}$ strains, and the curves have a flatter shape.

The microstructures observed in the samples quenched

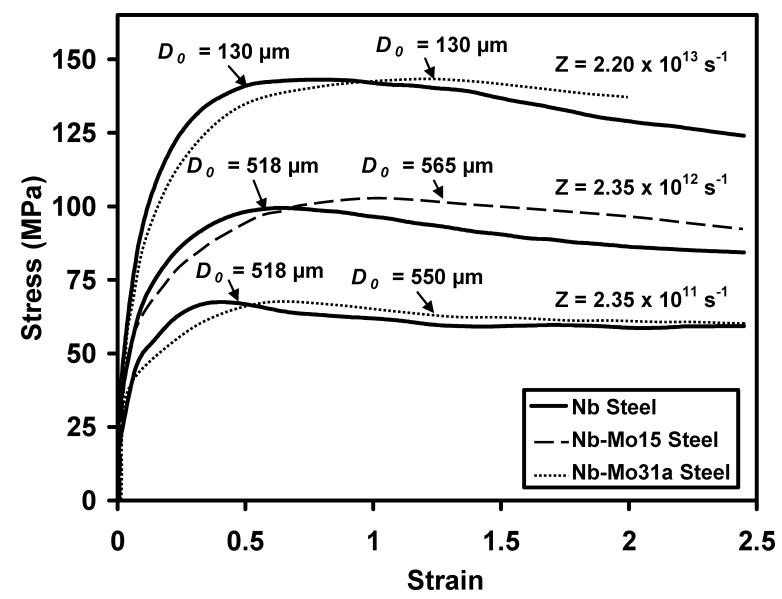

Fig. 4. Comparison of stress-strain curves for $\mathrm{Nb}$ and $\mathrm{Nb}-\mathrm{Mo}$ steels at three deformation conditions with similar initial austenite grain sizes.

after different strains at $1100^{\circ} \mathrm{C}$ and $\dot{\varepsilon}=1 \mathrm{~s}^{-1}$ (see flow curves in Fig. 2) are shown in Fig. 5, denoting that the unrecrystallized areas are progressively consumed as the dynamically recrystallized fronts migrate into the deformed matrix. Figures 5(a1)-(c1) correspond to an initial austenite grain size of $130 \mu \mathrm{m}$ while Figs. 5(a2)-(c2) corresponds to an initial austenite grain size of $650 \mu \mathrm{m}$. In Figs. 5(a1)-(b1) and (a2)-(b2) dynamic recrystallization is only partial, with the microstructure highly being heterogeneous, while Figs. $5(\mathrm{c} 1)$ and (c2) show complete recrystallization. At the initial stages of the process new grains nucleate predominantly at the parent austenite grain boundaries, although they are not homogeneously distributed in the matrix and tend to form in clusters. It must be noted that the microstructures shown in Figs. 5(a1) and (a2) correspond to quenching deformations very close to the peak strains measured at each condition, respectively. The recrystallized fraction was quantified for these samples, the results being represented as a function of deformation in Fig. 6 for the two grain sizes. The recrystallized fraction increases with the applied strain. As it is shown in the figure, the evolution of the dynamically recrystallized fraction can be described by the Avrami type equation:

$$
X_{\mathrm{dyn}}=1-\exp \left(-\beta \cdot\left(\varepsilon-\varepsilon_{\mathrm{c}}\right)^{n}\right)
$$

with the same exponent for both conditions, $n=1.5$, and the $\beta$ parameter taking values of 1.3 for $D_{\mathrm{o}}=650 \mu \mathrm{m}$ and 2.5 for $D_{\mathrm{o}}=130 \mu \mathrm{m}$ conditions, respectively. The Avrami exponent value is in the range between 1 and 2 , the typical value in literature for microalloyed steels. ${ }^{21,22)}$ In the figure the characteristic strains, $\varepsilon_{\mathrm{c}}, \varepsilon_{\mathrm{p}}$ and $\varepsilon_{\mathrm{ss}}$, determined from the flow curves are also shown. The recrystallized $\left(D_{\mathrm{r}}\right)$ and unrecrystallized $\left(D_{\mathrm{u}}\right)$ grain sizes were quantified for the different strains and the average values are listed in Table 2. It can be seen that the dynamically recrystallized grain size slightly increases during the process, leading to similar values for both initial grain sizes, confirming that the DRX grain size is independent of the initial microstructure.

From the stress-strain curves the values of $\varepsilon_{\mathrm{p}}$ and $\varepsilon_{\mathrm{c}}$ have been worked out. The $\varepsilon_{\mathrm{c}} / \varepsilon_{\mathrm{p}}$ ratios determined for both steels are quite similar, in the range of 0.7 and 0.84 , without the initial microstructure or deformation conditions affect- 

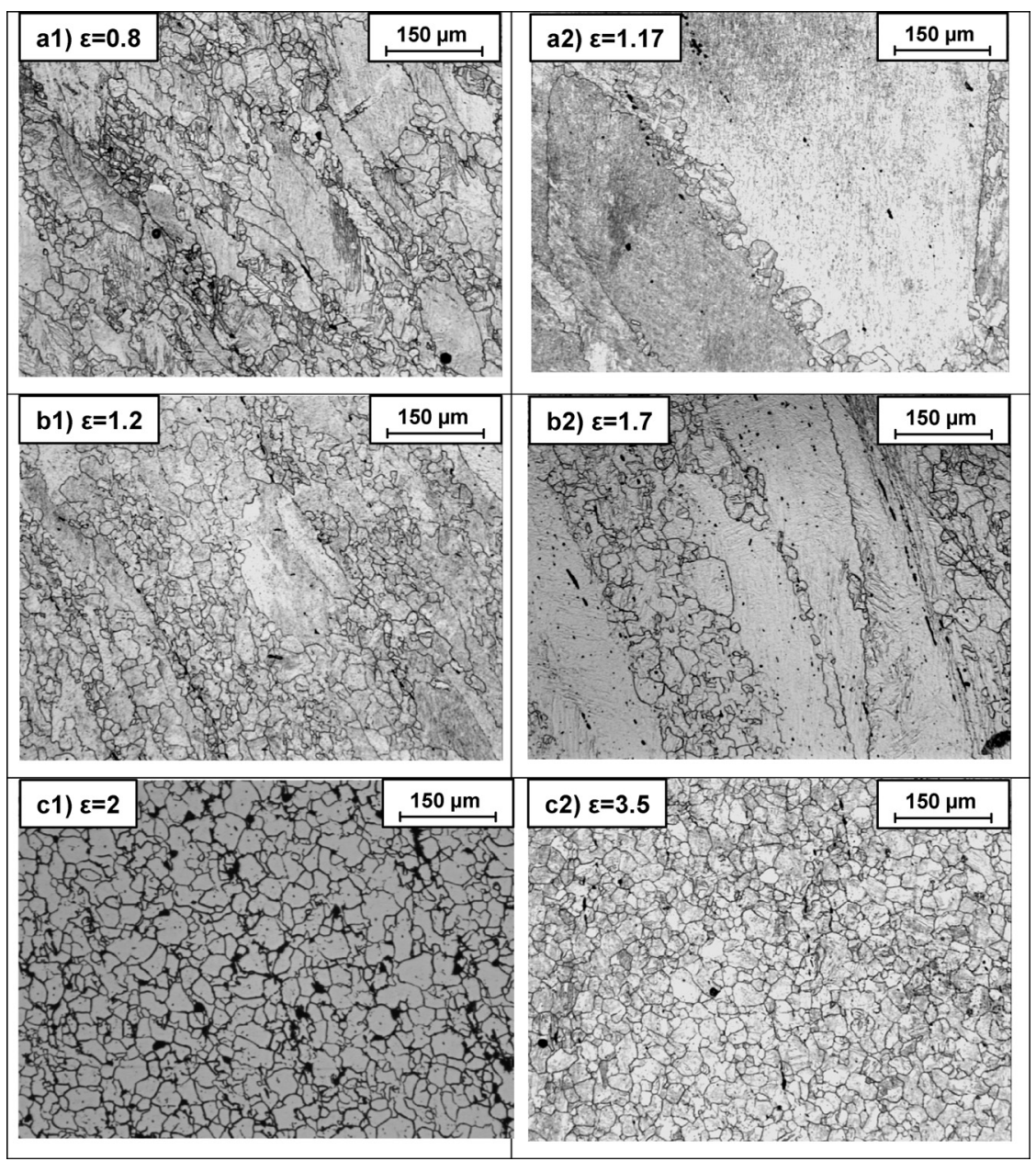

Fig. 5. Microstructural evolution during deformation for the $\mathrm{Nb}-\mathrm{Mo} 31 \mathrm{a}$ steel tested at $1100^{\circ} \mathrm{C}$ and a strain rate of $1 \mathrm{~s}^{-1}$ Micrographs a1, b1 and c1 correspond to $D_{\mathrm{o}}=130 \mu \mathrm{m}$ and micrographs a2, b2 and c2 to $D_{\mathrm{o}}=650 \mu \mathrm{m}$. The deformation level is indicated in the micrographs.

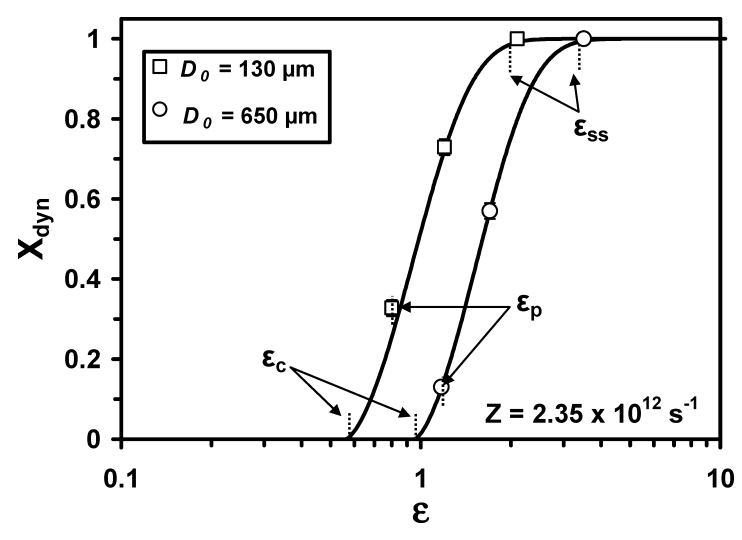

Fig. 6. Evolution of the dynamically recrystallized fraction with strain for the data shown in Fig. 2. The solid line represents the fit of the experimental data to an Avrami type equation.

ing this ratio. The mean value of $\varepsilon_{\mathrm{c}} / \varepsilon_{\mathrm{p}}=0.77$ has been taken for the five steels investigated. Figure 7 shows the good correlation between the adopted relationship and the experimental results.

\section{Discussion}

\subsection{Austenite Grain Coarsening}

The different grain coarsening behavior observed in Fig.
Table 2. Recrystallized volume fraction, $X_{\mathrm{dyn}}$, average recrystallized grain sizes $D_{\mathrm{r}}$ and unrecrystallized $D_{\mathrm{u}}$ grain sizes for $\mathrm{Nb}-\mathrm{Mo} 31 \mathrm{a}$ steel. The strains at which samples have been quenched are shown. The $95 \%$ confidence limits are included.

\begin{tabular}{|c|c|c|c|c|}
\hline$D_{o}(\mu \mathrm{m})$ & $\varepsilon$ & $X_{d y n}$ & $D_{r}(\mu \mathrm{m})$ & $D_{u}(\mu \mathrm{m})$ \\
\hline \multirow{3}{*}{$650 \pm 50$} & 1.17 & $0.13 \pm 0.01$ & $14.5 \pm 0.6$ & $395 \pm 45$ \\
\cline { 2 - 5 } & 1.7 & $0.57 \pm 0.02$ & $18.8 \pm 0.9$ & $410 \pm 75$ \\
\cline { 2 - 5 } & 3.5 & 1 & $19.1 \pm 0.7$ & - \\
\hline \multirow{3}{*}{$130 \pm 4$} & 0.8 & $0.33 \pm 0.02$ & $14.6 \pm 0.7$ & $102 \pm 7$ \\
\cline { 2 - 5 } & 1.2 & $0.73 \pm 0.02$ & $15.3 \pm 0.6$ & $96.4 \pm 7.5$ \\
\cline { 2 - 5 } & 2 & 1 & $17.9 \pm 0.4$ & - \\
\hline
\end{tabular}

1 may be directly related to the composition of the steels. Grain growth can be affected by the solute drag effect of any elements in solid solution and by the pinning forces associated to precipitates. For the $\mathrm{Nb}$ steel, grain coarsening is expected to occur when the particles pinning the austenite grain boundaries start to dissolve. This is produced at around $1200^{\circ} \mathrm{C}$ in the $\mathrm{Nb}$ steel. It can be seen in the figure that this phenomenon occurs at higher temperatures, around $1300^{\circ} \mathrm{C}$, for the $\mathrm{Nb}-\mathrm{Mo}$ steels. The results from the use of Thermo-Calc software show that the Mo present in the 


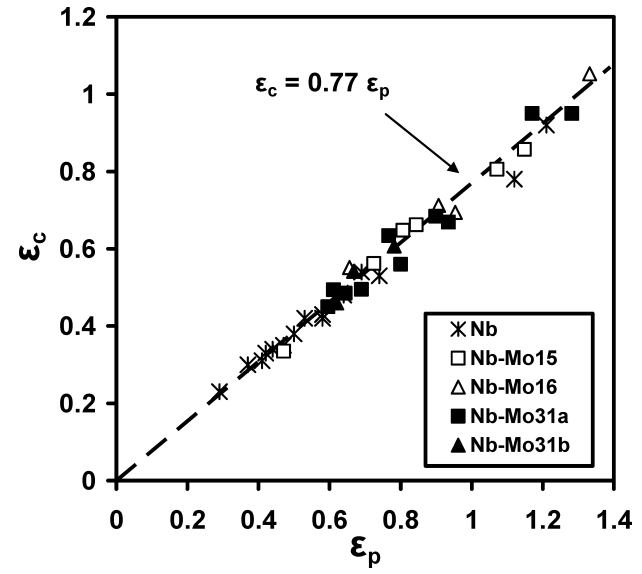

Fig. 7. Relationship between $\varepsilon_{\mathrm{c}}$ and $\varepsilon_{\mathrm{p}}$ values obtained for each deformation condition with $\mathrm{Nb}$ and the $\mathrm{Nb}-\mathrm{Mo}$ steels. The solid line represents an $\varepsilon_{\mathrm{c}} / \varepsilon_{\mathrm{p}}$ ratio equal to 0.77 .

steels is in solution over the whole austenitic range. These predictions agree well with the results of other authors ${ }^{1)}$ who do not report carbonitride precipitation in $\mathrm{C}-\mathrm{Mn}-\mathrm{Mo}$ steels. Regarding the nature of the precipitates formed in $\mathrm{Nb}-\mathrm{Mo}$ steels, there are some references indicating that Mo can be present in $\mathrm{Nb}(\mathrm{C}, \mathrm{N})$ particles as a residual element. ${ }^{23)}$ In contrast, other authors have not been able to detect any $\mathrm{Mo}$ in the $\mathrm{Nb}$ carbonitrides by using extraction replica techniques. ${ }^{24)}$

Therefore, the increase in grain coarsening temperature (GCT) observed in the $\mathrm{Nb}-\mathrm{Mo}$ steels compared to the $\mathrm{Nb}$ base steel can be attributed to the strong effect of Mo in solution, moving the GCT from about $1200^{\circ} \mathrm{C}$ in the $\mathrm{Nb}$ steel to values as high as $1300^{\circ} \mathrm{C}$ when Mo is added.

Nevertheless, it must be noted that no relationship is observed between grain coarsening behavior and the percentage of Mo in the steel. In fact, at the same reheating temperatures the $\mathrm{Nb}-\mathrm{Mo} 31 \mathrm{~b}$ steel, with the highest Mo content, has larger austenite grain sizes than the $\mathrm{Nb}-\mathrm{Mo} 16$ steel. The results indicate that the four $\mathrm{Nb}-\mathrm{Mo}$ steels, at reheating temperatures between $1400-1460^{\circ} \mathrm{C}$, bring similar austenite grain sizes in the range $530-650 \mu \mathrm{m}$, and do not depend on the amount of Mo present.

\subsection{Critical Strain for the Onset of Dynamic Recrys- tallization}

The previously determined relationship for $\mathrm{Nb}$ and $\mathrm{Nb}-$ Ti steels concerning the critical strain for the onset of DRX as a constant fraction of the peak strain, $\varepsilon_{\mathrm{c}}=0.77 \varepsilon_{\mathrm{p}}{ }^{18)}$ was found to be valid for $\mathrm{Nb}-\mathrm{Mo}$ steels too, as is shown in Fig. 7. This relationship is in the range of those reported in the literature for $\mathrm{C}-\mathrm{Mn}$ and microalloyed steels with coefficients varying between 0.4 and $0.86 .^{21,25-27)}$ The measurement of the onset of DRX can be difficult, and several evaluation methods have been proposed in other studies. The method used in this study took $\varepsilon_{\mathrm{c}}$ as the strain given by the inflection point in the $\theta-\sigma$ experimental curve, ${ }^{21)}$ being $\theta$ the strain hardening rate $\left(\theta=(\delta \sigma / \delta \varepsilon)_{\dot{\varepsilon}}\right)$. There are several factors that can explain the relative scatter observed in the literature for the $\varepsilon_{\mathrm{c}} / \varepsilon_{\mathrm{p}}$ ratio. The evaluation method and the type of deformation test used can significantly affect the measurement of $\varepsilon_{\mathrm{c}}{ }^{26)}$ apart from a possible dependence of this relationship on the material.

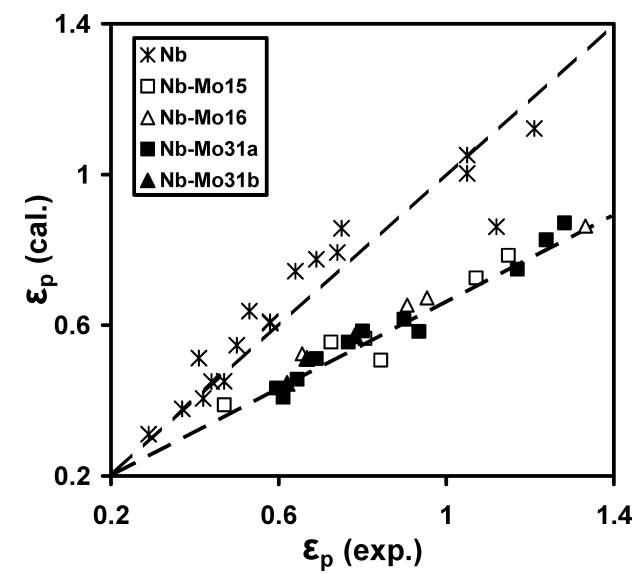

Fig. 8. Comparison between the $\varepsilon_{\mathrm{p}}$ experimental data and the predictions of Eq. (1) for all the steels studied.

\subsection{Dependence of $\varepsilon_{\mathrm{p}}$ and the $\varepsilon_{\mathrm{ss}}-\varepsilon_{\mathrm{c}}$ Strain Difference on Initial Microstructure and Deformation Condi- tions}

The effect of $\mathrm{Nb}$ and $\mathrm{Ti}$ in solid solution on the DRX kinetics was widely analyzed in reference ${ }^{18)}$ and the above mentioned Eq. (1) was proposed for the determination of the peak strain as a function of the amount of $\mathrm{Nb}$ and $\mathrm{Ti}$ in solution, initial microstructure and deformation conditions. The values given by Eq. (1) when applied to the $\mathrm{Nb}-\mathrm{Mo}$ steels are plotted in Fig. 8, these are contrasted against the experimental data determined from the flow curves. In the same figure the values corresponding to the $\mathrm{Nb}$ microalloyed base steel used as reference are also shown for comparison. It can be seen that the $\varepsilon_{\mathrm{p}}$ experimental values of $\mathrm{Nb}-\mathrm{Mo}$ steels are larger than those calculated with Eq. (1) in all cases whereas a good correlation is obtained for the $\mathrm{Nb}$ steel. These results indicate that there is a retardation on DRX kinetics in the Nb-Mo steels compared to the $\mathrm{Nb}$ microalloyed base material, in good agreement with the stress-strain curves shown in Fig. 4.

The same approach used for $\mathrm{Nb}$ and $\mathrm{Nb}-\mathrm{Ti}$ steels ${ }^{18)}$ was applied to quantify this effect. Thus, a corrective factor was introduced in Eq. (1) in order to quantify the Mo retardation effect, assuming that it is in solid solution, as follows:

$$
\begin{aligned}
\varepsilon_{\mathrm{p}}^{*} & =\frac{1.78 \cdot \varepsilon_{\mathrm{p}}}{3.7 \times 10^{-3}} D_{\mathrm{o}}^{-0.147} Z^{-0.155} \\
& =1+20([\mathrm{Nb}]+0.02[\mathrm{Ti}]+\beta[\mathrm{Mo}])
\end{aligned}
$$

The proportionality factor $\beta$ in Eq. (3) that minimizes the fitting errors in the modified parameter $\varepsilon_{\mathrm{p}}^{*}$ is $\beta=0.16$. Figure 9 shows the correlation between experimental and calculated values considering this contribution for Mo. Although the fitting could be considered reasonable for all the $\mathrm{Nb}-\mathrm{Mo}$ steels, the data corresponding to the highest Mo content steels (Nb-Mo31a-b) show a trend to be above the predictions, while the opposite is observed for the lowest Mo content ones (Nb-Mo15-16). These observations suggest that the retardation of DRX due to Mo may be independent of Mo content, at least in the range from 0.15 to $0.31 \%$ used in this study. What happens for Mo contents below $0.15 \%$ is not known. The effect of Mo probably increases as the amount of Mo increases, but reaches satura- 


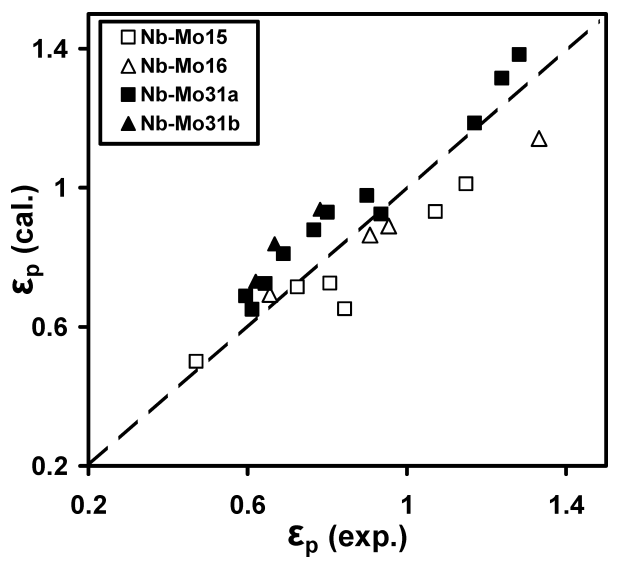

Fig. 9. Comparison between the $\varepsilon_{\mathrm{p}}$ experimental data and the predictions of Eq. (3) for the $\mathrm{Nb}-\mathrm{Mo}$ microalloyed steels.

tion point at a certain value. The problem is that there is not enough data to calculate when it occurs.

Taking the above into account the effect of Mo for the present results has been quantified through a constant factor, leading to the following generalized equation for the calculation of the peak strain in $\mathrm{Nb}, \mathrm{Nb}-\mathrm{Ti}$ and $\mathrm{Nb}-\mathrm{Mo}$ steels:

$$
\begin{aligned}
& \varepsilon_{\mathrm{p}}=3.7 \times 10^{-3} \frac{\{1+20([\mathrm{Nb}]+0.02[\mathrm{Ti}]+\Delta \cdot 0.035)\}}{1.78} \\
& \times D_{\mathrm{o}}^{0.147} Z^{0.155}
\end{aligned}
$$

where $\Delta=0$ for the $\mathrm{Nb}, \mathrm{Nb}-\mathrm{Ti}$ steels and $\Delta=1$ for $\mathrm{Nb}-\mathrm{Mo}$ steels. A good agreement between this generalized equation and the values of $\varepsilon_{\mathrm{p}}$ in the $\mathrm{Nb}-\mathrm{Mo}$ and $\mathrm{Nb}$ base steels is obtained, as shown in Fig. 10.

On the other hand, the strain difference $\left(\varepsilon_{\mathrm{ss}}-\varepsilon_{\mathrm{c}}\right)$ relates to the rate of dynamic recrystallization. Similarly to $\varepsilon_{\mathrm{p}}$, this magnitude depends on the initial austenite grain size, $D_{\mathrm{o}}$, and deformation conditions $(Z)$. The following relationship has been obtained by fitting the experimental results obtained in the present work with the different $\mathrm{Nb}-\mathrm{Mo}$ and $\mathrm{Nb}$ steels:

$$
\begin{aligned}
\varepsilon_{\mathrm{ss}}-\varepsilon_{\mathrm{c}}=1.16 \times 10^{-3} & \frac{\{1+20([\mathrm{Nb}]+0.02[\mathrm{Ti}]+\Delta \cdot 0.035)\}}{1.78} \\
& \times D_{\mathrm{o}}^{0.26} Z^{0.197} \ldots \ldots \ldots \ldots \ldots \ldots \ldots \ldots \ldots \ldots \ldots \ldots \ldots \ldots \ldots \ldots \ldots \ldots \ldots \ldots \ldots \ldots \ldots
\end{aligned}
$$

where as previously, $\Delta=0$ for the $\mathrm{Nb}, \mathrm{Nb}$ - Ti steels and $\Delta=1$ for $\mathrm{Nb}-\mathrm{Mo}$ steels. The degree of correlation between the values calculated using Eq. (5) and the experimental results can be observed in Fig. 11.

Likewise, the retardation effect of $\mathrm{Mo}$ in $\mathrm{Nb}$ microalloyed steels was studied by Akben et al. ${ }^{3)}$ in steels containing $0.31 \%$ Mo through the solute retardation parameter (S.R.P.). These authors also observed an important retardation of recrystallization caused by Mo addition, although it must be indicated that the steels used in this study show a larger Mo retardation effect than the one observed by Akben et al. ${ }^{3)}$

\subsection{Dynamically Recrystallized Microstructure}

In Fig. 12 the mean grain size of the dynamically recrystallized austenite is plotted in a double logarithmic scale

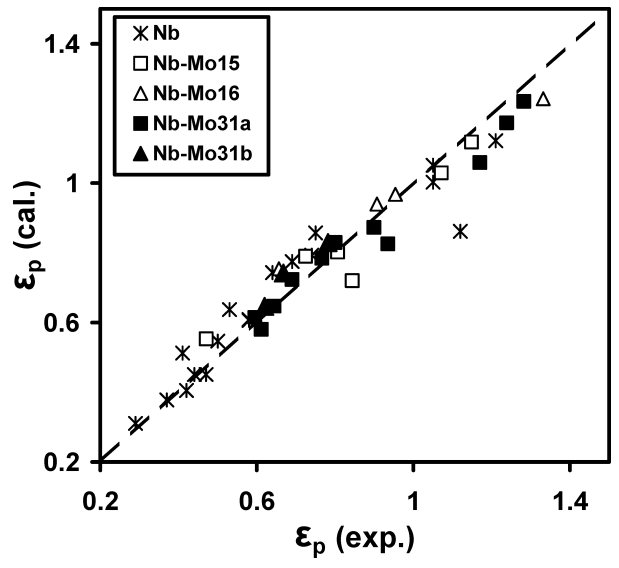

Fig. 10. Comparison between the $\varepsilon_{\mathrm{p}}$ experimental data and the predictions of the generalized Eq. (4) for the different steels.

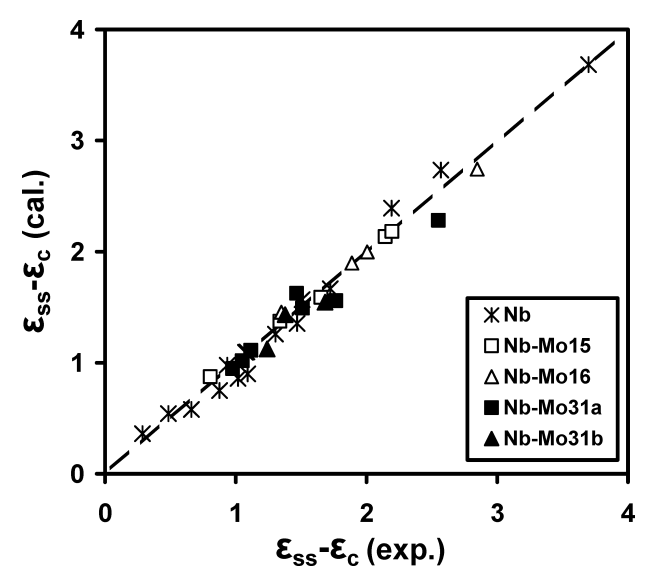

Fig. 11. Relationship between model predictions Eq. (5) and experimental $\left(\varepsilon_{\mathrm{ss}}-\varepsilon_{\mathrm{c}}\right)$ values.

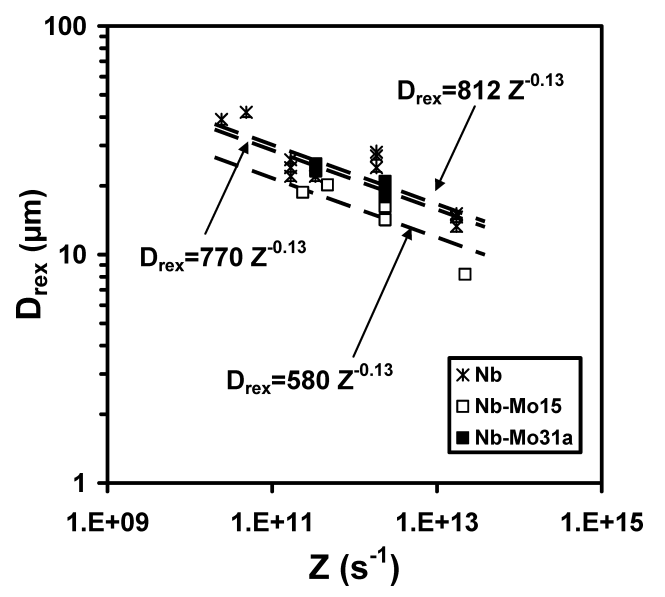

Fig. 12. Evolution of the mean dynamically recrystallized grain size with $Z$ for the $\mathrm{Nb}, \mathrm{Nb}-\mathrm{Mo} 15$ and $\mathrm{Nb}-\mathrm{Mo} 31$ a steels.

against the $Z$ parameter for the $\mathrm{Nb}$ steel, $\mathrm{Nb}-\mathrm{Mo} 15$ and $\mathrm{Nb}-\mathrm{Mo} 31 \mathrm{a}$ for those cases when steady state is reached before quenching. $Z$ was calculated using an activation energy value of $Q_{\mathrm{def}}=325 \mathrm{~kJ} / \mathrm{mol}^{18)}$ The figure denotes that the dynamically recrystallized grain size increases as $Z$ decreases. The various grain sizes plotted for the same value of $Z$, correspond to different initial microstructures and although there is experimental scatter, it can be concluded that the steady state microstructure is independent of the initial one, 
as is commonly reported in the literature..$^{15,16,28)}$ For a given composition a power relationship between the dynamically recrystallized grain size and the $Z$ parameter is usually proposed. ${ }^{28-30)}$ The set of data corresponding to each steel can be fitted to a power relationship, with the same exponent value $(-0.13)$ for all the materials, and the proportionality constant dependent on each steel:

a) $\mathrm{Nb}$ steel:

$$
D_{\text {rex }}=812 Z^{-0.13}
$$$$
\text { b) Nb-Mo31a steel: } \quad D_{\text {rex }}=770 Z^{-0.13}
$$$$
\text { c) } \mathrm{Nb}-\text { Mo15 steel: } \quad D_{\text {rex }}=580 Z^{-0.13}
$$

The exponent value $(0.13)$ is within the scatter of those reported in the literature: $0.11,{ }^{29)} 0.19,{ }^{30)} 0.2^{29)}$ and $0.35 .^{31)}$

It should be noted that both $\mathrm{Nb}-\mathrm{Mo}$ steels show a slightly smaller grain size than the $\mathrm{Nb}$ steel (see Fig. 12). DRX is essentially a process of repeated nucleation of the new recrystallized grains and limited growth, ${ }^{32-34)}$ the growing limitation of these grains being associated to the continuous strengthening because of the simultaneous deformation. ${ }^{16,21)}$ Thus, it can be postulated that the smaller size found in the $\mathrm{Nb}-\mathrm{Mo}$ steels is due to slower growth kinetics in these materials when compared to those only microalloyed with $\mathrm{Nb}$ because of an additional solute drag effect of the Mo.

Figure 13 shows the microstructures corresponding to different $Z$ values for the $\mathrm{Nb}-\mathrm{Mo} 15$ steel. It can be seen that for the lowest $Z$ value the grains are very irregular in shape, but as $Z$ increases the grains became smaller and more equiaxed. In the case of high $Z$ values, the higher dislocation accumulation results in a higher strain hardening of the new recrystallized grains. ${ }^{33)}$ As a consequence there is a reduction in the growing force and this leads to smaller dynamically recrystallized grain sizes. In contrast, as $Z$ diminishes strain hardening reduces, allowing faster growth of the new recrystallized grains in all directions, favoring the formation of more irregular DRX grains. Similar behavior was found in Ref. 18) for the $\mathrm{Nb}$ microalloyed base steel.

\subsection{DRX Fraction and Post-dynamic Softening Inter- action}

The amount of softening reached by dynamic processes (dynamic recovery and dynamic recrystallization) is an important issue regarding post-dynamic softening events. Usually, the critical strain for the onset of DRX is considered as indicative of the change in the mechanisms operating during subsequent post-dynamic softening, from static recrystallization (SRX) to metadynamic recrystallization (MDRX) mechanisms. ${ }^{17,26,35,36)}$ This change significantly affects the final microstructure since statically recrystallized grain size depends on initial microstructure and deformation degree, whereas, the metadynamically recrystallized grain size only depends on the $Z$ parameter and is finer than that produced by SRX. ${ }^{31,37)}$

Nevertheless, recent works have pointed out that the characteristics of MDRX process (large effect of strain rate but independent of strain) are only achieved after a minimum strain is reached, denoted as the transition strain, $\varepsilon_{\mathrm{T}}{ }^{38,39)}$ In practice this strain is related to the minimum amount of dynamically recrystallized fraction guaranteeing

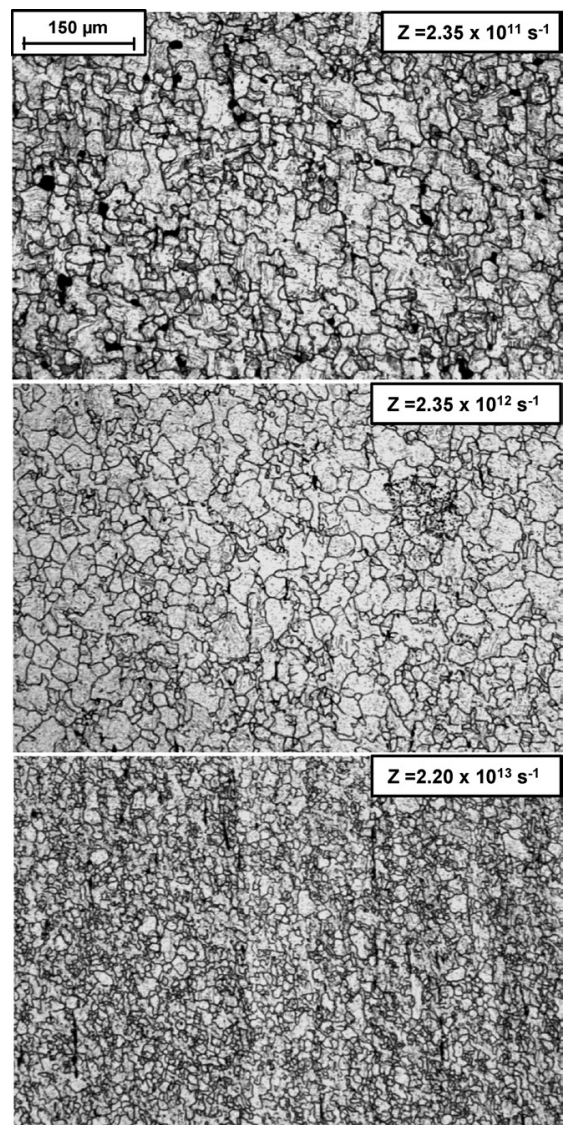

Fig. 13. Microstructures obtained for the $\mathrm{Nb}-\mathrm{Mo} 15$ steel with the values of $Z$ indicated at quenched strains higher than $\varepsilon_{\mathrm{ss}}$ ones $\left(D_{\mathrm{o}}=100 \mu \mathrm{m}\right)$.

that MDRX can account for a complete softening, assuming that this process only involves growth of previously nucleated dynamic grains. This minimum fraction would not be a constant value, but would depend on the initial grain size and deformation parameters. As initial grain size reduces, and taking into account geometrical considerations only, the amount of dynamically recrystallized fraction necessary to reach complete softening by metadynamic recrystallization mechanisms will tend to decrease. Similarly, decreasing $Z$ the dynamic and post-dynamic grain size increases, which may favor the completion of softening by metadynamic recrystallization. Between $\varepsilon_{\mathrm{c}}$ and $\varepsilon_{\mathrm{T}}$ a transition region is considered, where post-dynamic softening would be given by a combination of static and metadynamic recrystallization mechanisms. ${ }^{39)}$

A relationship of $\varepsilon_{\mathrm{T}}=K \varepsilon_{\mathrm{p}}$ has been reported, with $K$ taking values of $1.5^{38)}$ and $1.7 .^{39)}$ More recently, Hodgson et $a l$, considering different data from the bibliography together with their results, observed that the value of $K$ is related to the $D_{\text {rex }} / D_{0}$ ratio, with $D_{\text {rex }}$ the dynamically recrystallized and $D_{\mathrm{o}}$ the initial grain sizes, respectively. ${ }^{40)}$ Within the scatter, these authors have observed that when this ratio is lower than $\approx 0.3$, a decrease of $K$ with increasing $D_{\text {rex }} / D_{\text {o }}$ ratio is observed, with $K \approx 1$ for larger ratios.

Looking at Fig. 6, where the evolution of DRX fraction on the $\mathrm{Nb}-\mathrm{Mo} 31$ a steel for two different initial grain sizes is shown, one immediately recognizes the effect of grain size on the progression of the DRX process. As recrystallized grains nucleate in previous austenite grain boundaries, 
increasing the initial grain size, grain boundary area per unit volume decreases, producing a delay in the kinetics, as usually reported. ${ }^{15,16)}$ In Fig. 6 the peak strains determined for each condition have been indicated. It is observed that for the largest grain size of $650 \mu \mathrm{m}$, when $\varepsilon_{\mathrm{p}}$ is reached the amount of DRX fraction is relatively small, about $13 \%$. This result agrees with previous observations in the $\mathrm{Nb}$ base steel with a coarse grain size of $805 \mu \mathrm{m}$, where fractions $\sim 8-15 \%$ were measured close to the peak strain. ${ }^{18)}$ However, reducing the grain size to $130 \mu \mathrm{m}$ in Fig. 6 it is observed how the recrystallized fraction reached at $\varepsilon_{\mathrm{p}}$ increases to about $33 \%$. In this case, and applying Eq. (9), the $D_{\text {rex }} / D_{\text {o }}$ ratio would take values close to 0.14 and 0.03 for 130 and $650 \mu \mathrm{m}$, leading to values of $K \approx 1.38$ and 1.68 , respectively, close to those reported in Refs. 38) and 39). Taking these values, the transition strain calculated at each condition would be $\varepsilon_{\mathrm{T}} \approx 1.1$ and 1.96 for 130 and $650 \mu \mathrm{m}$, respectively. The respective DRX fractions associated to these strains in Fig. 6 are $64 \%$ and $73 \%$. These fractions are relatively high, probably due to the small size of dynamically recrystallized grains with respect to the initial grain size obtained under these deformation conditions.

The study of the evolution of the recrystallized fraction can help to define the aforementioned transition region. The competition between static and metadynamic recrystallization processes during post-dynamic softening will depend on the initial microstructure (grain size) and the deformation conditions ( $Z$ parameter), since both affect the evolution of the dynamically recrystallized fraction with strain.

Figures 14 and 15 show what the evolution of $\varepsilon_{\mathrm{T}}$ and $\varepsilon_{\mathrm{c}}$ with $Z$ would be, predicted for both the $\mathrm{Nb}-\mathrm{Mo} 31 \mathrm{a}$ and $\mathrm{Nb}$ steels, for the aforementioned initial grain sizes of 130 and $650 \mu \mathrm{m}$, respectively. The transition strain has been calculated as $\varepsilon_{\mathrm{T}}=K \varepsilon_{\mathrm{p}}$, assuming that $K$ varies with the ratio $D_{\text {rex }} / D_{\mathrm{o}}$ as in Ref. 40 ), and considering the experimentally determined relationship of $\varepsilon_{\mathrm{c}}=0.77 \varepsilon_{\mathrm{p}}$, the peak strain being determined from Eq. (4). The figure puts forward the reduction of the transition region (marked area) when the initial grain size diminishes for a given deformation conditions. The same occurs when the $Z$ parameter decreases. This brings a reduction in the $\varepsilon_{\mathrm{T}} / \varepsilon_{\mathrm{c}}$ ratio, which is an approximation of the $\varepsilon_{\mathrm{T}}$ transition strain to the $\varepsilon_{\mathrm{c}}$ critical strain, in better agreement with the identification of $\varepsilon_{\mathrm{c}}$ as the transition strain, as often reported in the literature for conventional grain sizes. ${ }^{17,26,35,36)}$ Furthermore, the retarding effect of Mo on DRX is clearly evident when comparing both steels. For a given grain size and deformation conditions, larger critical strains for the onset of the process and the amplification of the transition zone is observed when Mo is added.

As previously mentioned, the transition strain would be related to the minimum DRX fraction that guarantees that MDRX can account for a complete softening. The evolution of the dynamically recrystallized fraction, $X_{\text {dyn }}$, for a given test is described by Eq. (2). Assuming that $X_{\text {dyn }} \approx 0.99$ at the beginning of the steady state, i.e. for $\varepsilon=\varepsilon_{\mathrm{ss}}$, Eq. (2) can be expressed in terms of the steady state strain as follows:

$$
X_{\mathrm{dyn}}=1-\exp \left[-\frac{\ln 100}{\left(\varepsilon_{\mathrm{ss}}-\varepsilon_{\mathrm{c}}\right)^{n}}\left(\varepsilon-\varepsilon_{\mathrm{c}}\right)^{n}\right] \ldots \ldots \ldots
$$

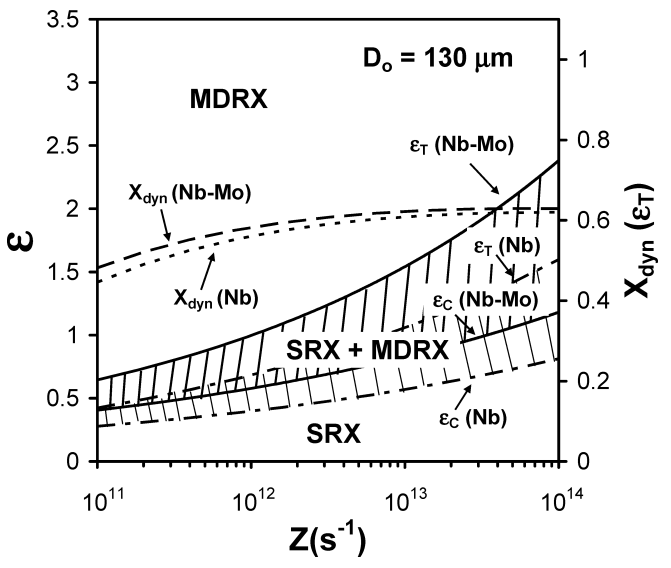

Fig. 14. Predicted ranges of static, metadynamic and mixed combination as a function of $\varepsilon$ and $Z$ for an initial grain size of $D_{\mathrm{o}}=130 \mu \mathrm{m}$ in both the Nb-Mo31a and the Nbbase steels. The predicted DRX fraction at the transition strain is plotted on the secondary axis $\left(X_{\mathrm{dyn}}\right)$.

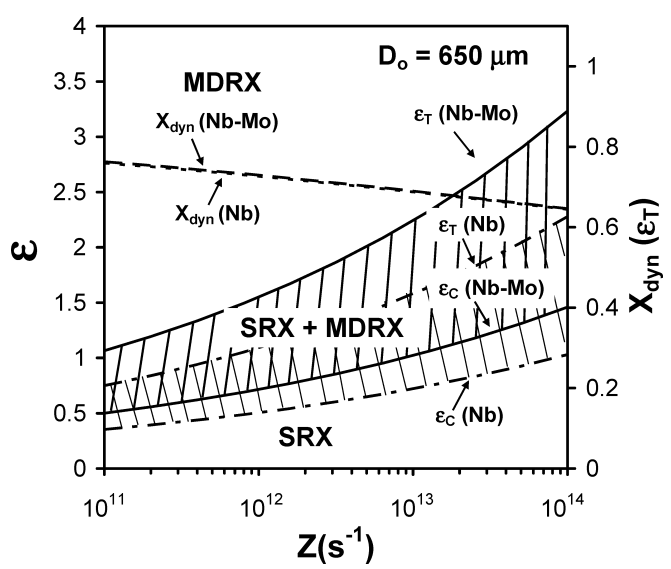

Fig. 15. Predicted ranges of static, metadynamic and mixed combination as a function of $\varepsilon$ and $Z$ for an initial grain size of $D_{\mathrm{o}}=650 \mu \mathrm{m}$ in both the Nb-Mo31a and the Nbbase steels. The predicted DRX fraction at the transition strain is plotted on the secondary axis $\left(X_{\mathrm{dyn}}\right)$.

where $n=1.5$ and the strain difference $\left(\varepsilon_{\mathrm{ss}}-\varepsilon_{\mathrm{c}}\right)$ is calculated from Eq. (5). With the help of Eq. (11) the amount of DRX fraction at the transition strain, $X_{\mathrm{dyn}}\left(\varepsilon_{\mathrm{T}}\right)$, can be estimated. These calculations are also represented in Fig. 14 and Fig. 15. For the deformation conditions shown in Fig. 6, $X_{\text {dyn }}\left(\varepsilon_{\mathrm{T}}\right)=60$ and $70 \%$ is calculated for 130 and $650 \mu \mathrm{m}$, respectively. It is observed that the predictions are very close to the results above, denoting that Eq. (11) reasonably describes the evolution of the experimentally observed DRX fraction. On the other hand there are no or only very small differences between both steels. It is obvious that by reducing the initial grain size a smaller amount of DRX fraction is required, although the differences tend to decrease as $Z$ increases, $X_{\text {dyn }}\left(\varepsilon_{\mathrm{T}}\right)$ being similar for the highest $Z$ values.

Regarding the effect of deformation conditions for a given microstructure, an increase in $X_{\mathrm{dyn}}\left(\varepsilon_{\mathrm{T}}\right)$ would be expected as $Z$ increases, since the dynamically recrystallized grain size would be smaller. However, this behavior is only observed for the lowest grain size, $130 \mu \mathrm{m}$. For the largest grain size, the DRX fraction tends to decrease slightly in both materials with increasing $Z$. Nevertheless, it must be noted that these changes are relatively small: $X_{\text {dyn }}\left(\varepsilon_{\mathrm{T}}\right)$ varies 
in the range $0.48-0.6$ and $0.76-0.64$ for 130 and $650 \mu \mathrm{m}$, respectively. These differences are small, not very far from the errors typically associated to the quantification of the recrystallized fraction in these materials. The results suggest that, regarding the extent of post-dynamic softening by MDRX mechanisms, the effect of initial grain size might be more important than the effect of deformation parameters, even if it seems to attenuate at very high $Z$ values.

\section{Conclusions}

(1) The influence of Mo addition on the kinetics of dynamic recrystallization in $\mathrm{Nb}$ steels was studied over a wide range of initial grain sizes $(22-805 \mu \mathrm{m})$. The characteristic strains, $\varepsilon_{\mathrm{c}}$ and $\varepsilon_{\mathrm{p}}$, were worked out for different deformation conditions and initial microstructures. A relationship of $\varepsilon_{\mathrm{c}}=0.77 \varepsilon_{\mathrm{p}}$ fitted the experimental results of $\mathrm{Nb}$ and $\mathrm{Nb}-$ Mo steels well.

(2) Molybdenum has a strong solute drag effect, both on the austenite grain size coarsening behavior and on the kinetics of dynamic recrystallization. However, this effect seems to be independent of the Mo content in the steel, at least in the range analyzed in the present study. A constant factor independent of Mo content was applied to modify a pre-existing $\varepsilon_{\mathrm{p}}$ equation to take this effect into account. As a result, it is possible to use a unique relationship applicable to $\mathrm{Nb}, \mathrm{Nb}-\mathrm{Ti}$ and $\mathrm{Nb}-\mathrm{Mo}$ steels for calculating the peak strain, $\varepsilon_{\mathrm{p}}$, as a function of deformation parameters $(Z)$, initial grain size $\left(D_{\mathrm{o}}\right)$ and the amounts of $\mathrm{Nb}$, Mo and Ti present in solid solution after each reheating treatment. Similarly, a unique relationship has been also derived for the rate of dynamic recrystallization in terms of the $\varepsilon_{\mathrm{ss}}-\varepsilon_{\mathrm{c}}$ strain difference.

(3) Using a constant factor to quantify the effect of Mo, independently of the Mo content in the $0.15-0.31 \%$ Mo range analyzed in this study, suggests saturation in the retardation effect of Mo on the DRX by solid solution.

\section{Acknowledgements}

The authors thank Niobium Products Company for providing some of the Mo-Nb heats. B. P. gratefully acknowledges a research grant from the Basque Government.

\section{REFERENCES}

1) B. Bacroix, M. G. Akben and J. J. Jonas: Proc. of Microalloyed Austenite, ed. by P. J. Wray and A. J. DeArdo, AIME, Warrendale, PA, (1982), 293.

2) W. B. Lee, S. G. Hong, C. G. Park, K. H. Kim and S. H. Park: Scr. Mater, 43 (2000), 319.

3) M. G. Akben, B. Bacroix and J. J. Jonas: Acta Metall., 31 (1983), 161.

4) S. F. Medina and C. A. Hernández: Acta Mater, 44 (1996), 149.

5) P. Uranga, A. I. Fernández, B. López and J. M. Rodriguez-Ibabe: 43rd MWSP Conf., Vol. 39, ISS, Warrendale, PA, (2001), 421.

6) P. Patel, C. Zhou and R. Priestner: Proc. 3rd Int. Conf. on Recrystal- lization and Related Phenomena, ReX'96, ed. by R. McNelley, Monterey, USA, (1997), 421.

7) C. A. Muojekwu, D. Q. Jin, I. V. Samarasekera and J. K. Brimacombe: 37th MWSP Conf., Vol. 33, ISS-AIME, Warrendale, PA, (1996), 617.

8) R. Priestner and C. Zhou: Ironmaking Steelmaking, 22 (1995), 326.

9) C. A. Muojekwu, D. Q. Jin, V. H. Hernández, I. V. Samarasekera and J. K. Brimacombe: 38th MWSP Conf., Vol. 34, ISS, Warrendale, PA, (1997), 351

10) J. M. Rodriguez-Ibabe: Mater. Sci. Forum, 500-501 (2005), 49.

11) P. Uranga, A. I. Fernández, B. López and J. M. Rodriguez-Ibabe: ISIJ Int., 44 (2004), 1416.

12) P. Uranga, A. I. Fernández, B. López and J. M. Rodriguez-Ibabe: 44th MWSP Conf., Vol. 40, ISS, Warrendale, PA, (2002), 945.

13) J. J. Jonas: Proc. of High Strength Low Alloy Steels Conf., ed. by D. P. Dunne and T. Chandra, Port Kembla, Australia, (1984), 80.

14) G. Akben and J. J. Jonas: Proc. of High Strength Low Alloy Steels Conf., ed. by D. P. Dunne and T. Chandra, Port Kembla, Australia, (1984), 149.

15) Roberts, H. Bodén and B. Ahlblom: Met. Sci., 13 (1979), 195.

16) J. P. Sah, G. J. Richardson and C. M. Sellars: Met. Sci., 8 (1974), 325.

17) W. P. Sun and E. B. Hawbolt: ISIJ Int., 37 (1997), 1000.

18) A. I. Fernández, P. Uranga, B. López and J. M. Rodriguez-Ibabe: Mater. Sci. Eng. A, A361 (2003), 367.

19) P. Uranga, A. I. Fernández, B. López and J. M. Rodriguez-Ibabe: Mater. Sci. Forum, 500-501 (2005), 245.

20) G. Glover and C. M. Sellars: Metall. Mater. Trans., 3 (1972), 2271.

21) N. D. Ryan and H. J. McQueen: Can. Metall. Q., 29 (1990), 147.

22) S. F. Medina and C. A. Hernández: Acta Mater., 44 (1996), 1650.

23) S. K. Mishra, S. Das and S. Ranganathan: Mater. Sci. Eng. A, A323 (2002), 285.

24) H. Watanabe, Y. E. Smith and R. D. Pehlke: ISS-AIME, New York, USA, (1977), 140.

25) E. Anelli: ISIJ Int., 32 (1992), 440.

26) A. Kirihata, F. Siciliano, Jr., T. M. Maccagno and J. J. Jonas: ISIJ Int., 38 (1998), 187.

27) F. Siciliano and J. J. Jonas: Metall. Mater. Trans. A, 31A (2000), 511.

28) M. Carsi, V. López, F. Peñalba and O. A. Ruano: Mater. Sci. Eng. A, A216 (1996), 155.

29) J. L. Nazábal, J. J. Urcola and M. Fuentes: Mater. Sci. Technol., 86 (1987), 93.

30) L. E. Cepeda, J. M. Rodriguez-Ibabe and J. J. Urcola: Mater. Sci. Forum, 113-115 (1993), 399.

31) P. D. Hodgson, J. J. Jonas and S. Yue: Mater. Sci. Forum, 113-115 (1993), 473.

32) I. Weiss, T. Sakai and J. J. Jonas: Met. Sci., 18 (1984), 77.

33) C. M. Sellars: Mater. Sci. Forum, 113-115 (1993), 29.

34) Ph. Bocher and J. J. Jonas: Proc. Int. Conf. on Recrystallization and Related Phenomena, Rex'99, ed. by T. Sakai and H. G. Suzuki, The Japan Institute of Metals, Sendai, Japan, (1999), 25.

35) C. M. Sellars: Proc. Int. Conf. on Hot Working and Forming Processes, ed. by C. M. Sellars and G. J. Davies, Metals Society, London, (1980), 3.

36) K. Minami, F. Siciliano, Jr., T. M. Maccagno and J. J. Jonas: ISIJ Int., 36 (1996), 1507.

37) C. Roucoules, S. Yue and J. J. Jonas: Metall. Mater. Trans. A, 26A (1995), 181.

38) D. Q. Bai, S. Yue and J. J. Jonas: Proc. of the J. J. Jonas Symp. on Thermomechanical Processing of Steel, ed. by S. Yue and E. Essadiqi, Metals Society, Ottawa, Canada, (2000), 669.

39) P. Uranga, A. I. Fernández, B. López and J. M. Rodriguez-Ibabe: Mater. Sci. Eng. A, 345A (2003), 319.

40) M. R. Cartmill, M. R. Barnett, S. H. Zahiri and P. D. Hodgson: ISIJ Int., 45 (2005), 1903. 